\title{
Low-dose modified-release prednisone in axial spondyloarthritis: 3-month efficacy and tolerability
}

This article was published in the following Dove Press journal:

Drug Design, Development and Therapy

14 November 2016

Number of times this article has been viewed

\section{Francesca Bandinelli' \\ Francesco Scazzariello' \\ Emanuela Pimenta da \\ Fonseca $^{2}$ \\ Mittermayer Barreto \\ Santiago ${ }^{2}$ \\ Claudio Marcassa ${ }^{3}$ \\ Francesca $\mathrm{Nacci}^{1}$ \\ Marco Matucci Cerinic'}

'Department of Experimental and Clinical Medicine, University of

Florence, Florence, Italy; ${ }^{2}$ Service of Rheumatology, Hospital Santa Isabel, Escola de Medicina e Saúde Pública, Bahia, Brazil; ${ }^{3}$ Maugeri Clinical and Scientific Institutes, IRCCS, Veruno, Novara, Italy
Correspondence: Francesca Bandinelli Department of Experimental and Clinical Medicine, University of Florence, Largo Brambilla 3, IT 50139 Florence, Italy Tel +393387472303

Fax +39055749 927I

Email bandin@hotmail.it
Background: Oral glucocorticoids (GCs) have been shown to be effective in reducing the inflammatory symptoms of rheumatoid arthritis, but their use is not supported by evidence in spondyloarthritis (SpA). Modified-release (MR) oral prednisone taken at bedtime has been shown to be more effective than immediate-release prednisone taken in the morning. The efficacy of low-dose MR prednisolone in patients with SpA is unknown.

Patients and methods: This single-center cohort study retrospectively assessed the effectiveness and safety of 12-week low-dose MR prednisone ( $5 \mathrm{mg}$ daily, bedtime administration) in GC-naïve adult patients with symptomatic axial SpA. A 50\% improvement of the Bath Ankylosing Spondylitis Disease Activity Index (BASDAI) or a final BASDAI score of $<4$ according to disease activity at baseline was chosen as the primary outcome parameter after MR prednisone.

Results: Fifty-seven patients were evaluated; of them, 41 had an active disease (BASDAI score of $\geq 4$ ) at baseline. MR prednisone significantly reduced BASDAI (from 5.5 \pm 2.6 to 3.0 \pm 2.8 , $P<0.001)$ as well as inflammatory symptoms, pain, fatigue and morning stiffness. The overall response rate after MR prednisone was 52.6\% (53.7\% in patients with active $\mathrm{SpA}$ and $50.0 \%$ in patients with low-active disease; nonsignificant). At multivariable analysis, none of the considered clinical findings independently predicted the response to MR prednisone in subjects with active SpA. Overall, seven patients (11.8\%) had nonserious adverse drug reactions after MR prednisone.

Conclusion: In patients with symptomatic SpA and naïve to GCs, low-dose MR prednisone reduced the symptoms and clinical indexes of disease activity and showed a positive safety profile.

Keywords: spondyloarthritis, morning stiffness, glucocorticoids, modified-release prednisone

\section{Introduction}

Spondyloarthritis $(\mathrm{SpA})$ is one of the most common chronic immune-mediated inflammatory diseases, affecting $\sim 0.5 \%-1.5 \%$ of the Western population. SpA comprises ankylosing spondylitis (AS), psoriatic arthritis, arthritis/spondylitis with inflammatory bowel disease and reactive arthritis; patients with typical features of SpA not fulfilling the criteria for one of the above-mentioned subtypes have also been incorporated in the $\mathrm{SpA}$ concept (undifferentiated forms). SpA usually involves the spine, entheses, and peripheral joints, ${ }^{1}$ and its pathogenesis is quite different from that of rheumatoid arthritis, with different major histocompatibility complex molecules, ${ }^{2}$ as well as predisposing and susceptibility factors. ${ }^{3}$

The clinical presentation of SpA is characterized by the presence of active inflammatory symptoms, particularly in the early stage, with pain and stiffness; although SpA can also be distinguished according to the clinical presentation as predominantly peripheral or axial, some overlap between these two subtypes often occurs. Psoriasis, uveitis, and inflammatory bowel disease frequently coexist. ${ }^{4-6}$ 
Control of signs and symptoms and reduction of inflammation parameters are key treatment targets in axial and peripheral SpA., ${ }^{1,7}$ According to the joint Assessment of Spondyloarthritis International Society (ASAS)/European League Against Rheumatism (EULAR), nonsteroidal anti-inflammatory drugs (NSAIDs), including the selective cyclooxygenase-2 (COX-2) antagonists, are recommended as first-line drug treatment of pain and stiffness in $\mathrm{SpA} ; ;^{7,9-11}$ tumor necrosis factor (TNF)- $\alpha$ blocking agents are recommended in unresponsive subjects or in patients intolerant to NSAIDs. ${ }^{7,12}$

Unlike rheumatoid arthritis, neither conventional diseasemodifying antirheumatic drugs (DMARDs) nor glucocorticoids (GCs) are recommended in the treatment of axial SpA, ${ }^{7}$ and the evidence for their efficacy in this context is limited and controversial.

However, GCs could be helpful in patients with uncontrolled peripheral joint manifestations, particularly in the absence of effective alternative first-line treatment options (ie, patients intolerant or with contraindications to NSAIDs). More recently, oral prednisolone $50 \mathrm{mg}$ /day showed a shortterm response significantly higher than placebo, but not low-dose prednisolone. ${ }^{13}$

Given the complex interactions between the hypothalamicpituitary-adrenal axis and the activated immune system, there are circadian variations in serum cortisol, TNF- $\alpha$ and interleukin-6 levels; the latter two peaking early in the morning. ${ }^{14}$ Conventional GCs are usually administered in the morning; such administration would be suboptimal, since peak plasma steroid concentrations occur well after the circadian inflammatory cytokines rise. On the contrary, inflammation, pain, and morning stiffness might be better controlled by anticipating the traditional administration of GCs, thus adapting the release of GCs to the rhythms of endogenous cortisol and cytokines. To these aims, a modified-release (MR) oral prednisone has been developed, and its use has been approved in rheumatoid arthritis in Europe. Administered at bedtime, its timing of drug release early in the morning (at about $02.00 \mathrm{am}$ ) better suits the circadian rhythms of inflammation and symptoms, with a clinically relevant reduction in pain and morning stiffness compared to conventional prednisone. ${ }^{15}$

The efficacy of low-dose MR prednisolone in patients with $\mathrm{SpA}$ is unknown. Therefore, the aim of this preliminary study was to assess the midterm clinical efficacy and safety profile of low-dose MR prednisone in GC-naïve patients with axial SpA refractory or intolerant to NSAIDS or with comorbidities limiting TNF- $\alpha$ blocking agents.

\section{Patients and methods}

This 12-week, single-center, retrospective, observational analysis was performed using data from patients treated at the Rheumatologic Unit of the University of Florence, Florence, Italy. The study was performed in accordance with Italian legislation on the protection of personal data and with the approval of the institutional review board of the University Hospital of Florence (Italy) (protocol number 2015/00 16289). All patients signed informed consent for the anonymous collection of their demographic and clinical data.

Data from all GC-naïve adult patients aged $>18$ years who were referred to the authors specialist center with a diagnosis of axial SpA according to ASAS criteria ${ }^{16}$ from September 2012 to December 2013 were reviewed. Patients refractory, intolerant or with contraindications to NSAIDS and/or with comorbidities limiting TNF- $\alpha$ blocking agents who, in the absence of contraindications, were prescribed MR prednisone were included in this study. Patients were not included in the study if, at the time of their first MR prednisone prescription, they were already receiving other steroids. Other exclusion criteria were presence of other rheumatic diseases or chronic infections, severe mechanical axial comorbidities unrelated to SpA, or neurological disorders with motor, and cognitive or sensitive impairment and active cancer. Pregnant females, patients with cognitive impairment not allowing an appropriate pain assessment, and subjects with a history of alcohol and drug abuse were also excluded.

At baseline (T0), patients were visited by specialized clinicians trained in the management of AS and prescribed MR prednisone $5 \mathrm{mg}$ daily (Lodotra ${ }^{\circledR}$ tablets, bedtime administration at about $10.00 \mathrm{pm}$ ). Patients were seen or contacted by phone calls or email after 4 weeks (T1); if well tolerated, no dose adjustments of MR prednisone were done; otherwise it was interrupted. Thereafter, all patients were reevaluated 8 weeks later (T2), thus after 12 weeks on MR prednisone. Given the low steroid dosage prescribed, no specific bone or gastric protectors were recommended. Other medications used for the treatment of any other underlying medical conditions were continued with their dosage unchanged. Adverse events or other inconvenience related to MR prednisone was investigated.

\section{Efficacy and safety parameters}

Disease activity was measured at baseline and the T2 visit by the Bath Ankylosing Spondylitis Disease Activity Index (BASDAI, scores $\geq 4 / 10$ indicating an active disease, according to EULAR recommendation). ${ }^{17}$ Presence 
and severity of symptoms were evaluated on a verbally administered 0-10 numerical rating scale (with 0 indicating the absence and 10 an extremely severe symptom). At baseline and T2, fatigue and morning stiffness duration ( $\mathrm{min}$ ) were also measured, as well as spinal mobility, measured by Bath Ankylosing Spondylitis Metrology Index (BASMI score of $0-10) .{ }^{18}$ Other serial evaluations included the entheseal pain, investigated using the Maastricht Ankylosing Spondylitis Enthesitis Score (MASES of $0-13) ;^{19}$ the number of swollen and tender joints (66/68-joint score) and the presence of dactylitis, sacroiliac, axial, and peripheral pain at palpation. Laboratory outcome assessments included erythrocyte sedimentation rate (ESR) and CRP levels at baseline and T2.

Safety evaluations were also performed with the recording of adverse drug-related reactions (ADRs) that occurred after the first intake of MR prednisone or worsened in intensity and/or frequency thereafter. ADRs were collected via spontaneous reports and patient visits, and the potential correlation between the ADR and the study drug was judged by the visiting rheumatologist. Only ADRs of moderate degree (ie, those symptoms causing a low level of inconvenience or concern that interferes with daily activities and functioning, requiring MR prednisone dose tapering or not permitting the dose escalation) or severe degree and requiring treatment discontinuation were considered. Serious adverse events associated with the use of MR prednisone were also recorded. ${ }^{20}$

\section{Statistical analysis}

The primary efficacy measure of the study was the response rate to MR prednisone at week-12 visit, defined according to BASDAI values at baseline and changes in disease activity throughout the observation: in subjects with a baseline BASDAI score of $\geq 4$, the response to MR prednisone was defined as a final BASDAI score of $<4,{ }^{21}$ in patients with a baseline BASDAI score of $<4$, response to therapy was defined as a $\geq 50 \%$ improvement of the BASDAI at T2.

To determine the size of the sample to be included in the analysis based on a Fleming's design, the null hypothesis was set at a response rate of at most $32 \%$ (ie, less than one-third of the considered population); the alternative hypothesis was set at a response rate of at least 51\% (more than half of the population), with a power of $80 \%$ and a significance level of 0.05 , and a minimum of 56 patients were needed.

The authors summarized data as mean and standard deviation for continuous variables and as the number (percentage) of study participants for categorical variables. Normal distribution of parameters was verified by the KolmogorovSmirnov test. The significance of differences between pairs of continuous variables was evaluated by the Student's $t$-test or the Wilcoxon test. A Student's $t$-test for unpaired data or analysis of variance was used to test differences between groups, with Bonferroni's correction when indicated. Changes over time in categorical variables were compared using the Cochran's $Q$ test. A Cox logistic regression analysis was used to identify the variables at baseline independently correlated with response to MR prednisone among those significantly associated on univariate analysis. All tests of significance were two-tailed, and a $P$-value of $<0.05$ was considered significant.

\section{Results}

Overall, 93 patients were screened and 59 fulfilled the selection criteria. Two of them stopped MR prednisone early for nonclinical reasons (poor compliance) and were excluded; the remaining 57 were included in the final analysis. All of them completed the 12-week follow-up. Patients' disposition is reported in Figure 1. Table 1 summarizes the baseline demographic and clinical characteristics of the analyzed population (median age 56 years, range 26-86 years; 65\% females). In about one-third of patients (32.2\%), the diagnosis of axial SpA dated $<1$ year. All patients had findings of sacroiliitis on magnetic resonance imaging. At baseline, three-fourth of the authors patients $(72.9 \%)$ had been treated with DMARDs and/or anti-TNF- $\alpha$ drugs. According to the baseline BASDAI, an active or low-active disease was present in $41(71.9 \%)$ and $16(28.1 \%)$ patients, respectively; the demographic and clinical data of the two subgroups are also reported in Table 1.

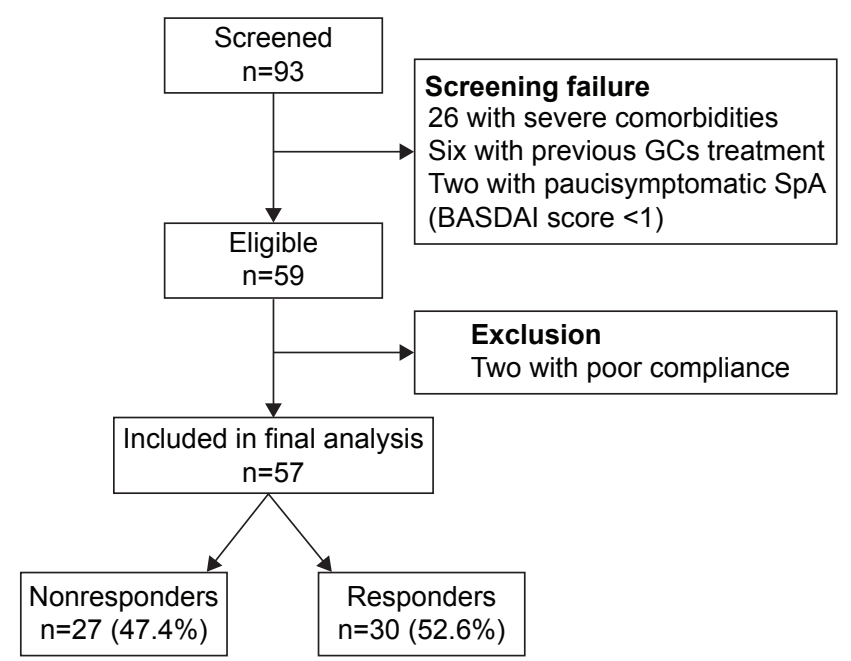

Figure I Patient disposition.

Abbreviations: GCs, glucocorticoids; BASDAI, Bath Ankylosing Spondylitis Disease Activity Index. 
Table I Demographic and clinical characteristics of the study population at baseline

\begin{tabular}{|c|c|c|c|c|}
\hline & $\begin{array}{l}\text { Overall } \\
\text { population }(n=57)\end{array}$ & $\begin{array}{l}\text { Low-active SpA } \\
(n=16,28.1 \%)\end{array}$ & $\begin{array}{l}\text { Active SpA } \\
(n=41,71.9 \%)\end{array}$ & $P$-value \\
\hline Age, years & $54.3 \pm 14.2$ & $54.7 \pm 14.5$ & $54.2 \pm 14.3$ & 0.91 \\
\hline Female sex, n (\%) & $37(64.9)$ & $6(37.5)$ & $30(73.2)$ & 0.016 \\
\hline Duration of the disease, years & $5.3 \pm 7.3$ & $7.0 \pm 11.9$ & $4.7 \pm 4.5$ & 0.31 \\
\hline \multicolumn{5}{|l|}{ Disease presentation, $\mathrm{n}(\%)$} \\
\hline Peripheral & $31(54.4)$ & $10(62.5)$ & $2 \mid(5 \mid .2)$ & 0.56 \\
\hline Entheseal & $17(29.8)$ & $3(18.7)$ & $14(34.1)$ & 0.34 \\
\hline Dactylitis & $14(24.6)$ & $4(25.0)$ & $10(24.4)$ & 0.96 \\
\hline \multicolumn{5}{|l|}{ Other inflammatory features, $\mathrm{n}(\%)$} \\
\hline Psoriasis & $27(47.4)$ & $10(62.5)$ & $17(42.5)$ & 0.19 \\
\hline Crohn's disease & $9(I 5.8)$ & $2(12.5)$ & $7(17.1)$ & 0.97 \\
\hline Ulcerative colitis & $4(7.0)$ & I (6.3) & $3(7.3)$ & 0.89 \\
\hline Uveitis & $2(3.5)$ & 0 & $2(4.9)$ & 0.96 \\
\hline \multicolumn{5}{|l|}{ Previous treatment, n (\%) } \\
\hline DMARDs & $42(73.7)$ & $7(43.7)$ & $35(85.4)$ & 0.004 \\
\hline Sulfasalazine & $18(31.6)$ & $3(18.7)$ & $15(36.6)$ & \\
\hline Methotrexate & $11(19.3)$ & $3(18.7)$ & $8(19.5)$ & \\
\hline Leflunomide & $7(12.3)$ & I (6.3) & $6(14.6)$ & \\
\hline Anti-TNF- $\alpha$ monotherapy & $3(5.3)$ & 0 & $3(7.3)$ & \\
\hline Anti-TNF- $\alpha+$ methotrexate & $\mathrm{I}(\mathrm{I} .7)$ & 0 & I (2.4) & \\
\hline Anti-TNF- $\alpha+$ sulfasalazine & $\mathrm{I}(\mathrm{I} .7)$ & 0 & $\mathrm{I}(2.4)$ & \\
\hline BASDAI score $(0-10)$ & $5.7 \pm 2.4$ & $2.8 \pm 0.7$ & $6.9 \pm 1.8$ & $<0.0001$ \\
\hline BASMI score $(0-10)$ & $1.5 \pm 1.9$ & $1.6 \pm 2.5$ & $1.5 \pm 1.6$ & 0.81 \\
\hline
\end{tabular}

Notes: All values are expressed as mean \pm SD or $n(\%)$. The sum of percentages may not be equal to 100 due to rounding.

Abbreviations: BASDAI, Bath Ankylosing Spondylitis Disease Activity Index; BASMI, Bath Ankylosing Spondylitis Metrology Index; DMARDs, disease-modifying antirheumatic drugs; SD, standard deviation; SpA, spondyloarthritis.

\section{Efficacy}

After 12 weeks on MR prednisone $5 \mathrm{mg}$ daily, a significant reduction in BASDAI was found in the overall population (from 5.5 \pm 2.6 to $3.0 \pm 2.8 ; P<0.001$ ). Axial and peripheral pain decreased from $5.2 \pm 3.9$ to $3.4 \pm 3.5(P=0.0013)$ and from $6.3 \pm 3.7$ to $3.8 \pm 3.7(P<0.001)$, respectively. The number of swollen and/or tender joints were also significantly reduced after 12 weeks on MR prednisone (from $2.8 \pm 7.9$ to $1.3 \pm 5$ $[P=0.002]$ and from $4.1 \pm 3.7$ to $2.5 \pm 3.4[P=0.002]$, respectively). Fatigue significantly improved (from $6.2 \pm 3.8$ to 3.6 $\pm 3.5 ; P<0.001$ ), severity of morning stiffness decreased (from $6.5 \pm 3.4$ to $3.3 \pm 3.6, P<0.0001$ ), as well as its duration (from 55.6 \pm 44.8 to $15.6 \pm 25.1 \mathrm{~min}, P<0.0001$ ). Dactylitis, found in 14 patients $(24.1 \%)$ at baseline, was still present after MR prednisone in only three patients $(5.1 \%, P<0.05$; odds ratio $0.15,95 \%$ confidence interval: $0.64-0.047$ ). On the contrary, only modest variations in BASMI and MASES were recorded (from $1.5 \pm 1.9$ to $1.2 \pm 1.6$ and from $2.9 \pm 4.3$ to $1.9 \pm 3.7$, respectively; nonsignificant [NS] for both variations). Axial, peripheral pain, fatigue, and morning stiffness at baseline and different time points after low-dose MR prednisone in patients with active or low-active SpA are shown in Figure 2.

Inflammatory markers also significantly declined after MR prednisone: ESR decreased from $20.3 \pm 16$ to
$15.4 \pm 13 \mathrm{~mm}(P<0.001)$ and CPR from $11 \pm 26$ to $4 \pm 6 \mathrm{mg} / \mathrm{L}$ $(P<0.05)$.

Overall, the response rate after 12 weeks was $52.6 \%$ (Figure 1): among the 16 patients who started MR prednisone with a low-active disease (BASDAI score of $<4$ ), the primary outcome parameter (ie, a 50\% improvement of the BASDAI at week 12$)$ was achieved in eight (50\%). A similar response rate $(n=22,53.7 \%$, NS) was documented in the 41 patients with active $\mathrm{SpA}$ at baseline.

\section{Patients with active SpA}

With regard to the subgroup of subjects with BASDAI values at baseline $\geq 4$, thus indicating active $S p A$, the baseline values and absolute changes for important secondary efficacy parameters after 12 weeks on MR prednisone in responders and nonresponders are reported in Table 2. At univariate analysis, responders had a longer disease duration $(P=0.03)$ and lower MASES, sacroiliac, axial, and peripheral pain scores at baseline ( $P=0.03, P=0.02$, and $P=0.01$, respectively). When the variables that significantly correlated with clinical response to MR prednisone by univariate analysis were introduced in the logistic regression model, none of them were found to be independent predictors of response $\left(\chi^{2}=2.2,0.34,2.9,2.8\right.$, and 3.6 for disease duration, MASES, sacroiliac, axial, and peripheral pain scores, respectively; all $P>0.05$ ). 
A

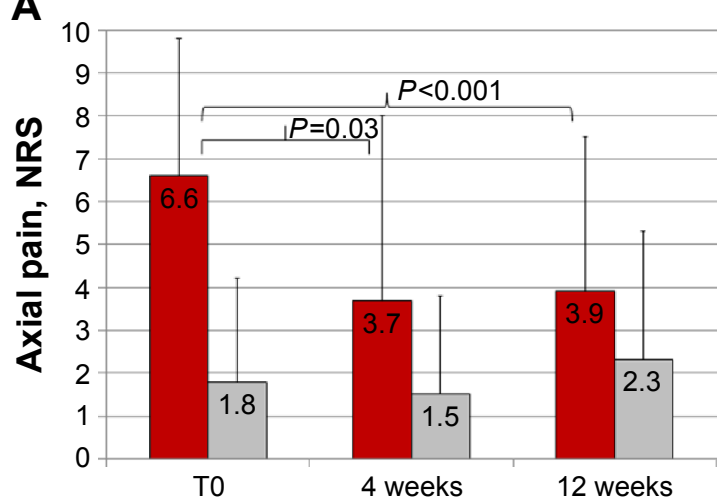

C

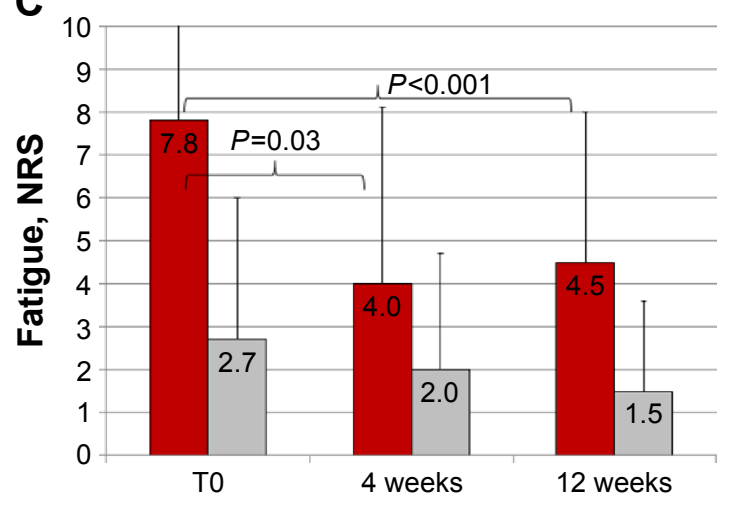

B

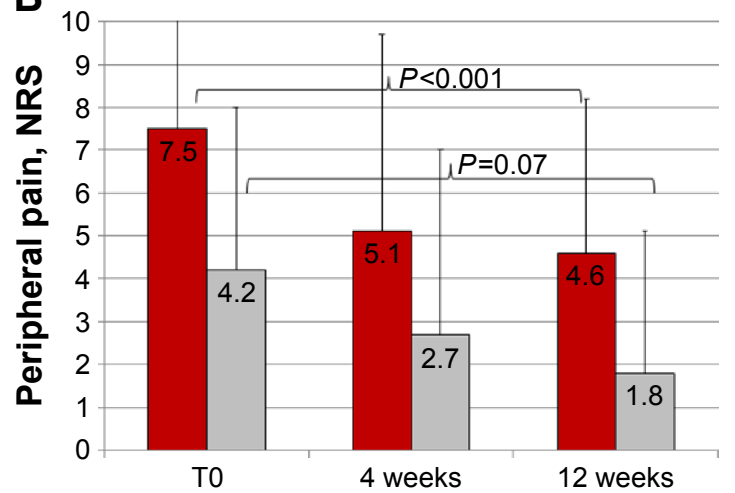

D

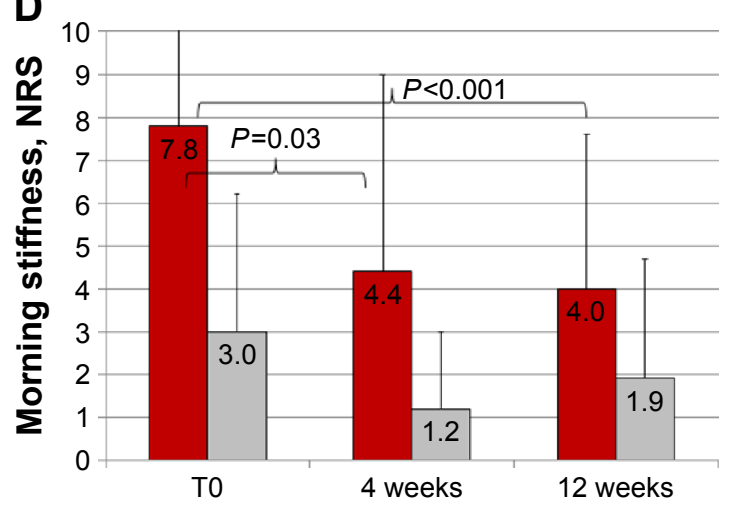

$\square$ Active $\square$ Low active

Figure 2 Axial pain (A), peripheral pain (B), fatigue (C), and morning stiffness (D) at baseline (T0) and different time points on low-dose MR prednisone in patients with active or low-active spondyloarthritis.

Notes: The significant differences within treatment groups at weeks 4 and 12 are reported. No other comparisons were significant. Abbreviations: T0, baseline evaluation; MR, modified-release; NRS, numerical rating scale.

\section{Safety}

Overall, the new treatment was well tolerated, and no serious adverse events occurred during the 12-week observation period. ADRs after MR prednisone were reported by seven patients (11.8\%): one severe ADR (1.7\%) occurred in a 69-year-old female complaining of aphthous stomatitis and panniculitis of the lower limbs; of note, symptoms disappeared after discontinuation of treatment, but did not reoccur after MR prednisone was reintroduced 3 months later due to disease reactivation after drug interruption. There were six other patients (10.2\%) reporting ADRs of moderate severity and requiring MR prednisone dose reduction (three patients with history of gastric intolerance to NSAIDs reported epigastric pain; two other patients reported leg tightness and one patient reported bilateral pretibial hematoma); all of them completed the 12-week drug observation.

\section{Discussion}

The anti-inflammatory and immunosuppressive effects of GCs are well characterized, although their precise mode of action is highly complex, eliciting different types of responses and with an adverse event profile depending on the target cell, type of GC, dosage, and administration route used..$^{22-24} \mathrm{GCs}$ are effective in relieving the signs and symptoms and interfering with radiographic progression in the treatment of rheumatoid arthritis and other inflammatory rheumatic diseases, either as monotherapy or in combination with synthetic DMARDs. ${ }^{17,22,25}$ On the contrary, there are limited data on their use in patients with SpA; although steroids administered locally have been proven effective when used intravenously ${ }^{26}$ or by computed tomography-guided injections into sacroiliac joints, ${ }^{27}$ the ASAS/EULAR recommendations for the management of SpA still state that the use of systemic GCs is not supported by evidence.?

Modern trials have confirmed that the efficacy of GCs can be significantly improved by administration as chronotherapy. ${ }^{28}$ In particular, low-dose MR prednisone effective at $02.00 \mathrm{am}$ inhibits the proinflammatory sequelae of nocturnal inflammation better than $\mathrm{GC}$ administration in the morning, alleviating signs and symptoms related to pathways of circadian cytokines without increasing the risk of hypothalamus-pituitary-adrenal axis insufficiency in rheumatoid arthritis. ${ }^{29}$ 
Table 2 Absolute changes in important clinical and laboratory variables in patients with active SpA after 12 weeks of treatment with low-dose MR prednisone

\begin{tabular}{|c|c|c|c|}
\hline Variables & $\begin{array}{l}\text { Responders } \\
(n=22)\end{array}$ & $\begin{array}{l}\text { Nonresponders } \\
(n=19)\end{array}$ & Difference \\
\hline \multicolumn{4}{|l|}{ BASDAI score $(0-10)$} \\
\hline Baseline & $6.5 \pm 1.7$ & $7.3 \pm 1.9$ & 0.18 \\
\hline Absolute change** & $5.0 \pm 1.9$ & $0.9 \pm 1.6$ & $<0.0001$ \\
\hline \multicolumn{4}{|l|}{ BASMI score $(0-10)$} \\
\hline Baseline & $1.4 \pm 1.9$ & $1.6 \pm 1.3$ & 0.74 \\
\hline Absolute change & $0.60 \pm 2.1$ & $0.10 \pm 1.9$ & 0.44 \\
\hline \multicolumn{4}{|l|}{ MASES $(0-13)$} \\
\hline Baseline & $2.5 \pm 4.1$ & $5.6 \pm 5.0$ & 0.03 \\
\hline Absolute change & $2.1 \pm 4.2$ & $1.0 \pm 5.1$ & 0.50 \\
\hline \multicolumn{4}{|l|}{ Axial pain $(0-10)$} \\
\hline Baseline & $5.5 \pm 4.1$ & $8.1 \pm 1.9$ & 0.02 \\
\hline Absolute change** & $4.4 \pm 4.5$ & $0.8 \pm 1.5$ & 0.02 \\
\hline \multicolumn{4}{|l|}{ Peripheral pain $(0-10)$} \\
\hline Baseline & $6.4 \pm 3.6$ & $8.8 \pm 1.7$ & 0.01 \\
\hline Absolute change** & $4.3 \pm 4.4$ & $1.1 \pm 2.4$ & 0.006 \\
\hline \multicolumn{4}{|l|}{ Sacroiliac pain $(0-10)$} \\
\hline Baseline & $0.68 \pm 0.89$ & $\mathrm{I} .4 \pm 0.84$ & 0.001 \\
\hline Absolute change & $0.14 \pm 0.94$ & $0.16 \pm 1.4$ & 0.95 \\
\hline \multicolumn{4}{|l|}{ Fatigue $(0-10)$} \\
\hline Baseline & $7.4 \pm 3.0$ & $8.3 \pm 2.5$ & 0.29 \\
\hline Absolute change** & $5.0 \pm 3.7$ & $1.3 \pm 2.4$ & 0.0007 \\
\hline \multicolumn{4}{|c|}{ Morning stiffness severity $(0-10)$} \\
\hline Baseline & $7.9 \pm 2.4$ & $7.8 \pm 2.7$ & 0.97 \\
\hline Absolute change** & $6.1 \pm 2.6$ & $1.3 \pm 2.7$ & $<0.0001$ \\
\hline \multicolumn{4}{|c|}{ Morning stiffness duration (min) } \\
\hline Baseline & $7 I \pm 42$ & $58 \pm 44$ & 0.36 \\
\hline Absolute change* & $65 \pm 38$ & $25 \pm 33$ & 0.001 \\
\hline \multicolumn{4}{|l|}{$\mathrm{ESR}(\mathrm{mm})$} \\
\hline Baseline & $22.8 \pm 19.6$ & $19.0 \pm 15.3$ & 0.51 \\
\hline Absolute change & $4.9 \pm 9.3$ & $3.8 \pm 7.4$ & 0.67 \\
\hline \multicolumn{4}{|l|}{ CRP (mg/L) } \\
\hline Baseline & $0.96 \pm 1.3$ & $1.4 \pm 4.0$ & 0.64 \\
\hline Absolute change & $0.6 \pm 1.2$ & $1.0 \pm 4.1$ & 0.61 \\
\hline
\end{tabular}

Notes: All values are expressed as mean \pm SD. *Interaction at week 12 between the subgroups, $P<0.01$. **Interaction at week 12 between the subgroups, $P<0.0001$. Abbreviations: BASDAI, Bath Ankylosing Spondylitis Disease Activity Index; BASMI, Bath Ankylosing Spondylitis Metrology Index; CRP, C-reactive protein; ESR, erythrocyte sedimentation rate; MASES, Maastricht Ankylosing Spondylitis Enthesitis Score; MR, modified-release; SD, standard deviation; SpA, spondyloarthritis.

In the authors retrospective trial, the efficacy of MR prednisone was assessed under real-life conditions over a medium-term observation period of 3 months. Despite the low steroid dosages prescribed, the authors found a substantial improvement of fatigue, pain, and morning stiffness, a significant reduction in inflammatory markers, as well as in BASDAI scores. Interestingly, the severity and duration of morning stiffness and number of tender and/or swelling joints were more likely to benefit from low-dose MR prednisone. On the contrary, sacroiliac pain and BASMI score were substantially unchanged after 12 weeks, and MASES decreased only slightly after MR prednisone. Sacroiliac pain, an efficacy parameter not easy-to-use and rarely used to monitor AS improvements in clinical trials, is generally more severe in early than in late stages of disease. BASMI, a parameter indicating loss of axial mobility, and indirectly, permanent damage, not surprisingly, was higher in patients with low disease activity, who also had longer disease duration. MASES encompasses the extent of enthesitis; of note, baseline MASESs were significantly higher in patients with active disease (BASDAI score of $\geq 4$ ) and in nonresponders to MR prednisone, in whom sacroiliac, as well as peripheral pain, was also more severe, with a disease of shorter duration. Speculatively, low-dose MR prednisone might be more effective at midterm on synovitis (ie, on arthritis) rather than enthesitis-predominant disease. However, in the authors study, at multivariable analysis none of the clinical parameters investigated by univariate and multivariable analysis independently correlated with response to low-dose MR prednisone. Thus, the prediction of those subjects with active SpA who will mostly benefit from low-dose MR prednisone could not be considered straightforward, based only on clinical data. Although the authors cannot exclude that it is the limited number of subjects evaluated that drive such inconclusive findings at multivariable analysis, a more likely explanation is that the clinical parameters taken into consideration are somehow related to each other.

To the authors knowledge, only one placebo-controlled double-blind multicenter trial has prospectively explored the short-term (2-week) efficacy of higher dosages of GCs in patients with active AS. In a small number $(n=39)$ of patients who were younger and with a greater disease duration than the authors study cohort, Haibel et $\mathrm{al}^{13}$ found that oral prednisolone $50 \mathrm{mg}$ daily, but not $20 \mathrm{mg}$, significantly improved several outcome parameters (ie, BASDAI, morning stiffness, patient global assessment, BASMI, and Bath Ankylosing Spondylitis Functional Index) compared with those of placebo. In that study, the BASDAI score reduction after 2 weeks of 20 and $50 \mathrm{mg}$ oral prednisolone was -1.19 and -2.29 points from baseline values, respectively. Notably, of the authors 42 patients with active SpA at baseline, nearly half $(53.7 \%)$ responded, despite the very low dosages ( $5 \mathrm{mg}$ daily) of prescribed MR prednisone, with a BASDAI score reduction of -3.1 points after 3 months. Moreover, axial and peripheral pain and fatigue and morning stiffness were already significantly improved after 4 weeks (Figure 2) and then remained substantially unchanged.

Overall, the safety and tolerability profiles of lowdose MR prednisone treatment were good in this 12 -week 
observation. ADRs were reported in a small percentage of patients, none was serious, and although premature drug interruption was needed in three subjects, the reported side effects had a modest clinical impact. The small number of side effects associated with low-dose MR prednisone seems in accordance with the findings from CAPRA-2, which showed a good 3-month safety profile from MR prednisone in comparison with placebo. ${ }^{30}$

\section{Limitations}

The present study is the first suggesting the efficacy and tolerability of low-dose MR prednisone in SpA. This study has several limitations, including the retrospective design, the absence of a control group, and the short period of observation. However, the authors population is well representative of patients typically encountered in daily clinical practice with $\mathrm{SpA}$ and treated by office-based rheumatologists.

\section{Conclusion}

In this retrospective trial, a 12-week oral treatment with lowdose MR prednisone significantly reduced disease activity, fatigue, stiffness, and pain in steroid-naïve patients with SpA. Efficacy was accompanied by a positive safety profile. Taken together, these results suggest that low-dose MR prednisone, alone or in association with anti-TNF- $\alpha$ agents, might be a valuable therapeutic option in patients with SpA intolerant/ refractory to NSAIDs. Despite its limitations, the authors study may provide useful information and guidance for future studies to confirm the effective use of MR prednisone in this setting.

\section{Acknowledgments}

The authors thank Ray Hill, an independent medical writer, who provided English language editing and journal styling on behalf of Health Publishing and Services Srl. These services and the publication fee were funded by Mundipharma Pharmaceuticals Srl, Milano, Italy. The authors also thank Guya Piemonte, registered nurse (RN); Laura Benelli, RN; and Francesca Guidi, RN for their support in this study. The work was not supported by research funding.

\section{Disclosure}

The authors report no conflicts of interest in this work.

\section{References}

1. Paramarta JE, Baeten D. Spondyloarthritis: from unifying concepts to improved treatment. Rheumatology (Oxford). 2014;53(9):1547-1559.

2. Fendler C, Baraliakos X, Braun J. Glucocorticoid treatment in spondyloarthritis. Clin Exp Rheumatol. 2011;29(5 suppl 68):S139-S142.
3. Chatzikyriakidou A, Voulgari PV, Drosos AA. What is the role of HLAB27 in spondyloarthropathies? Autoimmun Rev. 2011;10(8):464-468.

4. Scarpa R, Peluso R, Atteno M. Clinical presentation of psoriatic arthritis. Reumatismo. 2007;59(suppl 1):49-51.

5. Peluso R, Di Minno MN, Iervolino S, et al. Enteropathic spondyloarthritis: from diagnosis to treatment. Clin Dev Immunol. 2013;2013:631408.

6. Peluso R, Iervolino S, Vitiello M, Bruner V, Lupoli G, Di Minno MN. Extra-articular manifestations in psoriatic arthritis patients. Clin Rheumatol. 2015;34(4):745-753.

7. Braun J, van den Berg R, Baraliakos X, et al. 2010 update of the ASAS/EULAR recommendations for the management of ankylosing spondylitis. Ann Rheum Dis. 2011;70(6):896-904.

8. Smolen JS, Braun J, Dougados M, et al. Treating spondyloarthritis, including ankylosing spondylitis and psoriatic arthritis, to target: recommendations of an international task force. Ann Rheum Dis. 2014; 73(1):6-16.

9. Dougados M, Gueguen A, Nakache JP, et al. Ankylosing spondylitis: what is the optimum duration of a clinical study? A one year versus a 6 weeks non-steroidal anti-inflammatory drug trial. Rheumatology (Oxford). 1999;38(3):235-244.

10. Sieper J, Klopsch T, Richter M, et al. Comparison of two different dosages of celecoxib with diclofenac for the treatment of active ankylosing spondylitis: results of a 12-week randomised, double-blind, controlled study. Ann Rheum Dis. 2008;67(3):323-329.

11. van der Heijde D, Baraf HS, Ramos-Remus C, et al. Evaluation of the efficacy of etoricoxib in ankylosing spondylitis: results of a fifty-two-week, randomized, controlled study. Arthritis Rheum. 2005;52(4):1205-1215.

12. van der Heijde D, Sieper J, Maksymowych WP, et al. 2010 Update of the international ASAS recommendations for the use of anti-TNF agents in patients with axial spondyloarthritis. Ann Rheum Dis. 2011;70(6): 905-908.

13. Haibel H, Fendler C, Listing J, Callhoff J, Braun J, Sieper J. Efficacy of oral prednisolone in active ankylosing spondylitis: results of a double-blind, randomised, placebo-controlled short-term trial. Ann Rheum Dis. 2014;73(1):243-246.

14. Cutolo M. Chronobiology and the treatment of rheumatoid arthritis. Curr Opin Rheumatol. 2012;24(3):312-318.

15. Santiago T, Jacobs JW, Saag KG, Buttgereit F, Pereira da Silva JA. Balancing the benefits and risks of low-dose glucocorticoid in rheumatoid arthritis. Acta Reumatol Port. 2015;40(1):10-22.

16. Rudwaleit M, van der Heijde D, Landewe R, et al. The development of assessment of spondyloarthritis international society classification criteria for axial spondyloarthritis (part II): validation and final selection. Ann Rheum Dis. 2009;68(6):777-783.

17. Smolen JS, Landewe R, Breedveld FC, et al. EULAR recommendations for the management of rheumatoid arthritis with synthetic and biological disease-modifying antirheumatic drugs. Ann Rheum Dis. 2010; 69(6):964-975.

18. Jones SD, Porter J, Garrett SL, Kennedy LG, Whitelock H, Calin A. A new scoring system for the Bath Ankylosing Spondylitis Metrology Index (BASMI). $J$ Rheumatol. 1995;22(8):1609.

19. Heuft-Dorenbosch L, Spoorenberg A, van Tubergen A, et al. Assessment of enthesitis in ankylosing spondylitis. Ann Rheum Dis. 2003;62(2): $127-132$.

20. U. S. Food and Drug Administration. [webpage on the Internet]. What is a Serious Adverse Event?. 2016. Available from: http://www.fda. gov/Safety/MedWatch/HowToReport/ucm053087.htm. Accessed April 29, 2016.

21. Garrett S, Jenkinson T, Kennedy LG, Whitelock H, Gaisford P, Calin A. A new approach to defining disease status in ankylosing spondylitis: the Bath Ankylosing Spondylitis Disease Activity Index.J Rheumatol. 1994;21(12):2286-2291.

22. Jacobs JW, Bijlsma JW. Glucocorticoids in rheumatology: indications and routes of administration. Clin Exp Rheumatol. 2011;29(5 suppl 68): S81-S84.

23. Strehl C, Spies CM, Buttgereit F. Pharmacodynamics of glucocorticoids. Clin Exp Rheumatol. 2011;29(5 suppl 68):S13-S18. 
24. Zen M, Canova M, Campana C, et al. The kaleidoscope of glucorticoid effects on immune system. Autoimmun Rev. 2011;10(6):305-310.

25. Gotzsche PC, Johansen HK. Short-term low-dose corticosteroids vs placebo and nonsteroidal antiinflammatory drugs in rheumatoid arthritis. Cochrane Database Syst Rev. 2004;3:CD000189.

26. Peters ND, Ejstrup L. Intravenous methylprednisolone pulse therapy in ankylosing spondylitis. Scand J Rheumatol. 1992;21(3):134-138.

27. Braun J, Bollow M, Seyrekbasan F, et al. Computed tomography guided corticosteroid injection of the sacroiliac joint in patients with spondyloarthropathy with sacroiliitis: clinical outcome and follow-up by dynamic magnetic resonance imaging. J Rheumatol. 1996;23(4): 659-664.
28. Spies CM, Straub RH, Cutolo M, Buttgereit F. Circadian rhythms in rheumatology-a glucocorticoid perspective. Arthritis Res Ther. 2014; 16(suppl 2):S3

29. Alten R, Doring G, Cutolo M, et al. Hypothalamus-pituitary-adrenal axis function in patients with rheumatoid arthritis treated with nighttimerelease prednisone. J Rheumatol. 2010;37(10):2025-2031.

30. Buttgereit F, Mehta D, Kirwan J, et al. Low-dose prednisone chronotherapy for rheumatoid arthritis: a randomised clinical trial (CAPRA-2). Ann Rheum Dis. 2013;72(2):204-210.

\section{Publish your work in this journal}

Drug Design, Development and Therapy is an international, peerreviewed open-access journal that spans the spectrum of drug design and development through to clinical applications. Clinical outcomes, patient safety, and programs for the development and effective, safe, and sustained use of medicines are the features of the journal, which has also been accepted for indexing on PubMed Central. The manuscript management system is completely online and includes a very quick and fair peer-review system, which is all easy to use. Visit http://www.dovepress.com/testimonials.php to read real quotes from published authors.

Submit your manuscript here: http://www.dovepress.com/drug-design-development-and-therapy-journal 